\title{
Reversion of P-Glycoprotein-Mediated Multidrug Resistance in Human Leukemic Cell Line by Diallyl Trisulfide
}

\author{
Qing Xia, ${ }^{1}$ Zhi-Yong Wang, ${ }^{2}$ Hui-Qing Li, ${ }^{3}$ Yu-Tao Diao, ${ }^{3}$ Xiao-Li Li, ${ }^{4}$ Jia Cui, ${ }^{5}$ \\ Xue-Liang Chen, ${ }^{1}$ and $\mathrm{Hao} \mathrm{Li}^{1}$ \\ ${ }^{1}$ Department of Hematology, Qilu Hospital, Shandong University, Shandong, Jinan 250012, China \\ ${ }^{2}$ Department of Emergency, Qilu Hospital, Shandong University, Shandong, Jinan 250012, China \\ ${ }^{3}$ Institute of Basic Medicine, Shandong Academy of Medical Sciences, Shandong, Jinan 250062, China \\ ${ }^{4}$ Soochow University and Department of Hematology, Branch Guangci of First Affiliated Hospital, Jiangsu, Suzhou 215128, China \\ ${ }^{5}$ Shouguang Centre for Disease Control and Prevention, Shouguang 262700, China
}

Correspondence should be addressed to Xue-Liang Chen, xlchen1999@163.com and Hao Li, haoli611@yahoo.com.cn

Received 15 February 2012; Accepted 16 May 2012

Academic Editor: Vincenzo De Feo

Copyright ( 2012 Qing Xia et al. This is an open access article distributed under the Creative Commons Attribution License, which permits unrestricted use, distribution, and reproduction in any medium, provided the original work is properly cited.

\begin{abstract}
Multidrug resistance (MDR) is the major obstacle in chemotherapy, which involves multiple signaling pathways. Diallyl trisulfide (DATS) is the main sulfuric compound in garlic. In the present study, we aimed to explore whether DATS could overcome Pglycoprotein-(P-gp-)mediated MDR in K562/A02 cells, and to investigate whether NF- $\kappa \mathrm{B}$ suppression is involved in DATS-induced reversal of MDR. MTT assay revealed that cotreatment with DATS increased the response of K562/A02 cells to adriamycin (the resistance reversal fold was 3.79) without toxic side effects. DATS could enhance the intracellular concentration of adriamycin by inhibiting the function and expression of P-gp, as shown by flow cytometry, RT-PCR, and western blot. In addition, DATS resulted in more K562/A02 cell apoptosis, accompanied by increased expression of caspase-3. The expression of NF- $\kappa \mathrm{B} / \mathrm{p} 65$ (downregulation) was significantly linked to the drug-resistance mechanism of DATS, whereas the expression of I $\kappa \mathrm{B} \alpha$ was not affected by DATS. Our findings demonstrated that DATS can serve as a novel, nontoxic modulator of MDR, and can reverse the MDR of K562/A02 cells in vitro by increasing intracellular adriamycin concentration and inducing apoptosis. More importantly, we proved for the first time that the suppression of NF- $\kappa$ B possibly involves the molecular mechanism in the course of reversion by DATS.
\end{abstract}

\section{Introduction}

The multidrug resistance (MDR) of leukemic cells to chemotherapy remains the most significant cause of treatment failure in acute leukemia [1]. A number of studies have shown that the major contributor to MDR is increased drug efflux mediated by P-glycoprotein (P-gp), a product of the mdr-1 gene $[2,3]$. Enormous efforts have been exerted to find reversal agents of the drug-efflux pump to overcome MDR [4]. Although hundreds of compounds have been found to reverse MDR, their clinical application is limited due to unacceptable side effects or toxicity at the doses required for effectiveness $[5,6]$. Therefore, searching for reversal agents with low toxicity and high reversal activity has become an important research task.
Many plant-derived drugs or herbal formulations have been proven to have antitumor potential in vitro and in vivo [7-9]. Many of them, such as carnosic acid, puerarin, and ampelopsin, may reverse P-gp-mediated MDR via a decrease in the expression of mdr-1 in K562/A02 cells, which is an adriamycin-selective, Pgp-overexpressing subline [1012]. However, there have been several reports which claimed that some of the plant-derived drugs could increase the P-GP function [13].

Diallyl trisulfide (DATS) is the main sulfuric compound in garlic. Garlic compounds have been shown to have antiviral, antibacterial, antioxidant, anti-inflammatory, antiproliferative, and antiangiogenic activities [14-19]. In vitro and in vivo preclinical studies have implicated DATS as an important mediator of cyclins and cell cycle arrest, apoptosis, 
cell adhesion, and angiogenesis [20-27]. Engdal proposed that garlic compounds could inhibit P-gp expression in vitro and in vivo [28]. DATS may have the ability to reverse drug resistance, but its molecular mechanism is still not fully understood.

We evaluated the P-gp-modulating potential of DATS in MDR K562/A02 cells to prove the effect of DATS as a reversal agent for human leukemic cells in vitro. In our previous study, the IC10 of DATS to K562/A02 cells was $2 \mu \mathrm{mol} / \mathrm{L}$, a noncytotoxic concentration dose also used in the present study. A verapamil-treated $(4 \mu \mathrm{g} / \mathrm{mL})$ group was used as positive control. Our goal was to ascertain whether transcription nuclear factor $\mathrm{B}(\mathrm{NF}-\kappa \mathrm{B})$ activation is involved in the reversal mechanism of DATS.

\section{Materials and Methods}

2.1. Drugs and Reagents. The following compounds were purchased: DATS (Shandong Lukang Xin Chen Pharmaceutical Co., Ltd., Shandong, China), verapamil (Shanghai Harvest Pharmaceutical Co., Ltd., Shanghai, China), adriamycin (ADM, Sigma Chemical Co., MO, USA), annexin V-FITC/PI (JingMei Bioengineering Co., Ltd., China), mouse antihuman P-gp monoclonal (BD Pharmingen Co., Ltd., USA), mouse antihuman mdr-1 antibody (Chemicon Co., Ltd., USA), rabbit anti-NF- $\kappa \mathrm{B}$ (P65) antibody and mouse antihuman $\mathrm{I} \kappa \mathrm{B} \alpha$ antibody (Cell Signaling Co., Ltd., USA), and caspase-3 rabbit antihuman monoclonal antibody (Beijing Biosynthesis Biotechnology Co., Ltd., Beijing, China). The primers were synthesized by Shanghai Boshang Biotechnology Co., Ltd. (Shanghai, China).

2.2. Cell Lines and Cell Culture. Human leukemia cell line K562 and its adriamycin-selective, Pgp-overexpressing subline K562/A02 were obtained from the Institute of Basic Medicine, Shandong Academy of Medical Sciences, China. Both cell lines were cultured in RPMI1640 medium (Gibco, Los Angeles, CA, USA) supplemented with $10 \%(\mathrm{v} / \mathrm{v})$ heatinactivated newborn calf serum (HangZhou Sijiqing Biological Engineering Materials Co., Ltd., China), $100 \mathrm{U} / \mathrm{mL}$ penicillin, and $100 \mu \mathrm{g} / \mathrm{mL}$ streptomycin. Furthermore, both cell lines were grown in a humidified incubator at $37^{\circ} \mathrm{C}$ and $5 \% \mathrm{CO}_{2}$. In particular, the K562/A02 cell line was maintained in $1 \mu \mathrm{g} / \mathrm{mL}$ adriamycin-containing medium and incubated in adriamycin-free medium for 2 weeks before the experiments.

2.3. Assay of In Vitro Drug Sensitivity. 3-(4,5-Dimethylthiazol-2-yl)-2,5-diphenyltetrazoliumbromide (MTT) assay was used to compare the MDR of the K562 and K562/A02 cells to adriamycin. K562 and K562/A02 cells were grown in a 96-well plate at $1 \times 10^{5}$ cells $/ \mathrm{mL}$ in a complete RPMI 1640 medium. Adriamycin was then added at various drug concentrations. K562 and K562/A02 cells without drugs in the medium were used as the blank controls. After the treatments were incubated for $44 \mathrm{~h}$ at $37^{\circ} \mathrm{C}, 20 \mu \mathrm{L}$ MTT was added into each well, and incubation continued for another $4 \mathrm{~h}$. The medium was then removed, and $150 \mu \mathrm{L}$ dimethyl sulfoxide was added to each well to dissolve the formazan crystals. The absorbance value was measured with a spectrophotometer at the wavelength of $570 \mathrm{~nm}$. IC50 of the drugs was calculated based on the MTT assay

Inhibition of cell viability

$$
\begin{gathered}
=1-\frac{\text { average } A \text { value of experimental group }}{\text { average } A \text { value of blank control group }} \times 100 \%, \\
\text { Drug resistance fold }=\frac{\text { IC50 of drug-resistant group }}{\text { IC50 of sensitive group }} .
\end{gathered}
$$

K562/A02 cells were seeded into 96-well culture plates at a density of $1 \times 10^{5}$ cells $/ \mathrm{mL}$ to determine whether DATS can sensitize MDR cells to the cytotoxicity of adriamycin. Adriamycin was then added with varying concentrations. The experimental group was treated with DATS at a concentration of $2 \mu \mathrm{mol} / \mathrm{L}$. Verapamil ( $4 \mathrm{mg} / \mathrm{L}$ ) treatment served as positive control. The cells were analyzed using the MTT method

$$
\text { Reverse fold }=\frac{\text { IC50 before reversal }}{\text { IC50 after reversal }} .
$$

2.4. Detection of Intracellular Adriamycin Concentration by FCM. The adriamycin concentration in K562/A02 cells was measured by flow cytometry (FCM). The K562 cells and K562/A02 cells without treatment were used as negative control. K562/A02 cells were treated with $2 \mu \mathrm{mol} / \mathrm{L}$ DATS or $4 \mathrm{mg} / \mathrm{L}$ verapamil and incubated for $48 \mathrm{~h}$ [29]. Adriamycin was then added to each sample to a final concentration

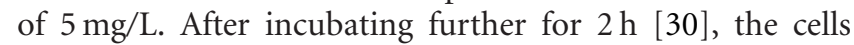
were harvested by centrifugation, washed twice with ice-cold phosphate buffered solution (PBS), and then resuspended in PBS. Adriamycin was excited effectively at a single wavelength $(488 \mathrm{~nm})$, and the emitted light was collected in the fluorescence-3 (FL3) channel. Events were gated on an FSC versus SCC dot plot to exclude the influences of cell debris and aggregates. A total of 10000 gated cells were detected for each sample, which were analyzed by Modfit LT software.

2.5. Detection of P-gp Expression by FCM. P-gp expression on the surface membrane of K562/A02 cells was determined by a direct immunofluorescence staining technique. K562/A02 cells were cocultured with $2 \mu \mathrm{mol} / \mathrm{L}$ DATS or $4 \mathrm{mg} / \mathrm{L}$ verapamil for $48 \mathrm{~h}$. They were washed twice and suspended in PBS. The cell suspension was incubated with phycoerythrin-conjugated UIC2, mouse antihuman P-gp monoclonal antibody (P-gp-PE), and the homotype control IgG2a-PE. The mixture was reacted at room temperature and away from light for $30 \mathrm{~min}$, washed twice, and then detected by FCM. The specific P-gp antibody UIC2 was detected in the FL-2 channel; thus, P-gp expression can be assessed on the cell surface. Protein expression was analyzed using Cell Quest software.

2.6. Observation of Morphological Changes by Light Microsc$o p y$. The morphological changes of apoptotic cells with 
hematoxylin-eosin (HE) staining were observed by light microscopy. K562/A02 cells were grown at $1 \times 10^{5}$ cells $/ \mathrm{mL}$ in a complete RPMI 1640 medium on a 24-well plate with a coverslip set at the bottom. After treatment with $2 \mu \mathrm{mol} / \mathrm{L}$ DATS combined with a final concentration of $1 \mathrm{mg} / \mathrm{L}$ adriamycin for $24 \mathrm{~h}$ to $72 \mathrm{~h}$, (treatment with adriamycin alone as control), the coverslip was removed in each experimental group. Using 95\% ethanol, the coverslip contents were fixed for $20 \mathrm{~min}$. A series of washings were then performed as follows: carefully washed with PBS two times, hematoxylin for $2 \mathrm{~min}$ to $3 \mathrm{~min}$, water to wash away hematoxylin for $1 \mathrm{~s}$ to $3 \mathrm{~s}, 1 \%$ hydrochloric acid and ethanol for $2 \mathrm{~s}$ to $3 \mathrm{~s}$ to reduce the cytoplasmic stain, lightly washed for $10 \mathrm{~s}$, ammonia for $10 \mathrm{~s}$ to $20 \mathrm{~s}$, and running water for $10 \mathrm{~s}$. Eosin staining was performed for $1 \mathrm{~m}$, then the stain was removed by washing with water for $1 \mathrm{~s}$ to $2 \mathrm{~s}, 80 \%$ ethanol $1 \mathrm{~s}$ to $2 \mathrm{~s}, 95 \%$ ethanol for $3 \mathrm{~min}$ to $5 \mathrm{~min}$, ethanol for $5 \mathrm{~min}$ to $10 \mathrm{~min}$, xylene (I) for $3 \mathrm{~min}$ to $5 \mathrm{~min}$, and xylene (II) for $2 \mathrm{~min}$ to $5 \mathrm{~min}$. The coverslip was then air-dried and mounted with neutral gum. Finally, the specimen was observed by light microscopy.

2.7. Apoptosis Assay by Statistical FCM. The apoptosis rates were measured using flow cytometric assay. Cell labeling was performed using annexin V conjugated to FITC, which binds to phosphatidylserine exposed on the surface membrane of cells undergoing apoptosis. After incubation in the medium containing different drugs $(2 \mu \mathrm{mol} / \mathrm{L}$ DATS or $4 \mathrm{mg} / \mathrm{L}$ verapamil) at $37^{\circ} \mathrm{C}$ for $48 \mathrm{~h}$, the cell suspensions were washed twice with PBS and centrifuged at $550 \times \mathrm{g}$ for $5 \mathrm{~min}$. The cells were suspended in $500 \mu \mathrm{L}$ binding buffer, $5 \mu \mathrm{L}$ annexin V-FITC, and $10 \mu \mathrm{L}(20 \mu \mathrm{g} / \mathrm{mL})$ PI solution incubated at room temperature for $15 \mathrm{~min}$ in the dark. The samples were measured using a flow cytometer with FACS software.

2.8. Semiquantitative RT-PCR Assay. After treatment with the drugs $(2 \mu \mathrm{mol} / \mathrm{L}$ DATS or $4 \mathrm{mg} / \mathrm{L}$ verapamil), in vitro total mRNA was extracted from the cells with trizol reagent (Invitrogen Co., CA, USA) according to the manufacturer's instructions. Single-stranded cDNA was synthesized by reverse transcription from $1 \mu \mathrm{g}$ of the total RNA using reverse transcriptase RNAse M-MLV (Invitrogen Co., CA, USA) and oligo-dT. The amplification was performed in a final volume of $50 \mu \mathrm{L}$, containing $5 \mu \mathrm{L}$ cDNA, $0.5 \mu \mathrm{L}$ of each oligonucleotide primer, $1 \mu \mathrm{L}$ of each $\mathrm{dNTP}$, and 1 unit of Taq DNA polymerase. Amplification was carried out in a thermal cycler. The PCR primers and expected product size were as follows: $\operatorname{mdr}-1\left(167 \mathrm{bp}\right.$ ) were $5^{\prime}-0-3^{\prime}$ (forward) and $5^{\prime}$-GTTCAAACTTCTGCTCCTCA-3' (reverse); $\beta$-actin (540 bp) were $5^{\prime}$-GTGGGGCGCCCCAGGCACCA$3^{\prime}$ (forward) and $5^{\prime}$-CTCCTTAATGTCACGCACGATTTC$3^{\prime}$ (reverse); NF- $\kappa \mathrm{B} / \mathrm{p} 65$ (293 bp) were $5^{\prime}$-TGCACCTAGCTGCCAAAGAAGGA-3' (forward) and 5'-TCTGCTCCTGCTGCTTTGAGAA-3' (reverse); I $\kappa \mathrm{B} \alpha$ (634 bp) were $5^{\prime}$ GCAGAGGATTACGAGCAGAT-3' (forward) and $5^{\prime}$-CCTGGTAGGTTACTCTGTTG-3' (reverse); Caspase-3 (358 bp) were $5^{\prime}$-CCCATTTCTCCATACGCACT-3' (forward) and $5^{\prime}$-TGACAGCCAGTGAGACTTGG-3' (reverse). The circulating conditions were as follows: $94^{\circ} \mathrm{C}$ for $1 \mathrm{~min}, 58^{\circ} \mathrm{C}$ for $1 \mathrm{~min}$, and $72^{\circ} \mathrm{C}$ for $1 \mathrm{~min}$ for 26 cycles, and then extended for $7 \mathrm{~min}$ at $72^{\circ} \mathrm{C}$. The products were identified by electrophoresis using $1.5 \%$ agarose gel. Using $\beta$-actin as internal reference, the products were further analyzed using Alpha gel image analysis system.

2.9. Western Blot Analysis of Protein Expression. After treatment with the drugs $(2 \mu \mathrm{mol} / \mathrm{L}$ DATS or $4 \mathrm{mg} / \mathrm{L}$ verapamil), total protein was isolated and subjected to sodium dodecyl sulfate PAGE analysis and transferred to a polyvinylidene difluoride membrane. The blots were stained with primary antibodies $(1: 1000-1200$, mouse anti-human mdr1 antibody, rabbit anti-human NF- $\kappa \mathrm{B}$ (P65) antibody, mouse anti-human $\mathrm{I} \kappa \mathrm{B} \alpha$ antibody, and rabbit anti-human caspase-3 monoclonal antibody) overnight at $4^{\circ} \mathrm{C}$, and then with horseradish peroxidase-conjugated goat antirabbit IgG $(1: 5000)$ for $1 \mathrm{~h}$ at room temperature. The signal was detected with an ECL Western blot detection kit (ZhongShan Co., Beijing, China). After normalization by the corresponding $\beta$-actin expression, protein expression level was determined by densitometry scans and measured with Quantity One software.

2.10. Analyses. Statistical calculations were carried out with SPSS 17.0 for Windows software package. The results were expressed as mean \pm standard deviation of three independent experiments. Student's $t$-test was used for the statistical analyses, and $P$ values $<0.05$ were considered significant. The synergetic effect of the two drugs was analyzed using factorial analysis.

\section{Results}

3.1. Drug Sensitivity. MTT assay was used to study the cytotoxicity of adriamycin. The ability of DATS at $2 \mu \mathrm{mol} / \mathrm{L}$ to enhance the cytotoxicity of adriamycin in K562/A02 was examined. The MTT assay results are summarized in Table 1. The IC50 value of adriamycin for K562/A02 decreased after treatment with DATS $(P<0.01)$. The time- and concentration-dependent reversal effects of DATS on the K562/A02 cells were observed for 24, 48, and $72 \mathrm{~h}$. The data of the three experiments are shown in Figure 1. The higher the concentration of DATS used, the better the inhibitive effect.

\subsection{Detection of Intracellular Adriamycin Concentration.} The effect of DATS on the intracellular accumulation of adriamycin was examined by FCM. The autofluorescence intensity of the K562 and K562/A02 cells was very low (Figures 2(a) and 2(b)). The fluorescence intensity of adriamycin in K562 cells was $4.24 \pm 0.15$, whereas it was $2.49 \pm 0.27$ in K562/A02 cells (Figures 2(c) and 2(d), $P<0.01$ ). After treatment with DATS, adriamycin fluorescence intensity in K562/A02 cells increased to $4.38 \pm 1.08$ (Figure 2(e)), showing a significant difference compared with that without DATS treatment cells $(P<0.01)$. These results showed that DATS can enhance the intracellular concentration of adriamycin. 
TABLE 1: IC50 of adriamycin in K562 and K562/A02 cells.

\begin{tabular}{|c|c|c|c|}
\hline Cell line & $\mathrm{IC} 50(\mathrm{ADM} \mu \mathrm{g} / \mathrm{mL})$ & Drug resistance fold & Reverse fold \\
\hline K562 & $0.11 \pm 0.037$ & & \\
\hline K562/A02 & $6.79 \pm 0.58$ & $61.73^{\Delta \Lambda}$ & \\
\hline K562/A02 + DATS & $1.80 \pm 0.348$ & & $3.79^{* *}$ \\
\hline K562/A02 + verapamil & $0.56 \pm 0.045$ & & $12.31^{* *}$ \\
\hline
\end{tabular}

$\Delta \mathbf{\Delta} P<0.01$ versus $\mathrm{K} 562,{ }^{* *} P<0.01$ versus K562/A02.

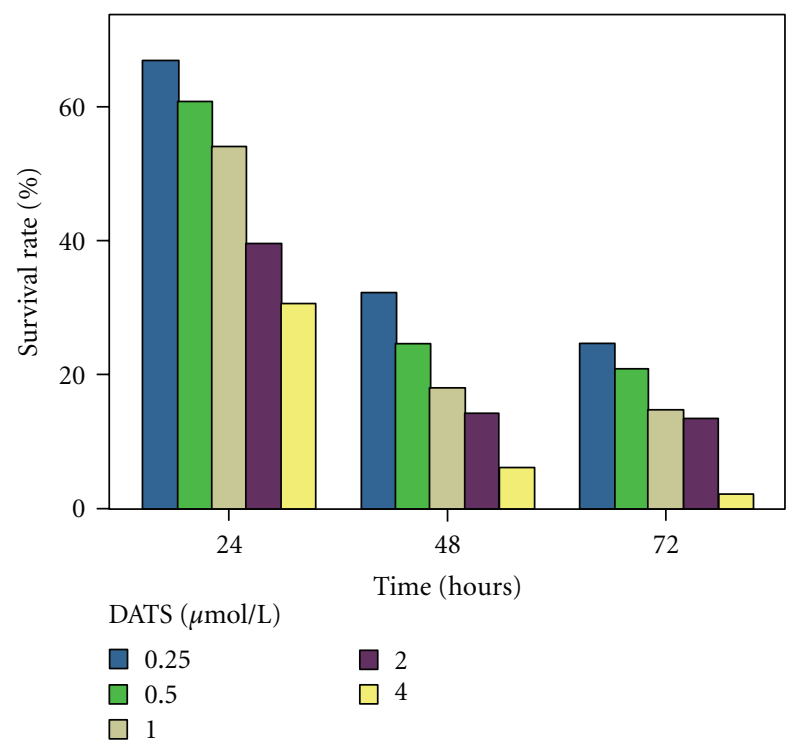

FIGURE 1: The time- and concentration-dependent reversal effects of DATS on the K562/A02 cells. K562/A02 cells were treated with adriamycin $(5 \mathrm{ug} / \mathrm{mL})$ for varying time intervals $(24 \mathrm{~h}, 48 \mathrm{~h}$, and $72 \mathrm{~h}$ ) in the presence of $0.25-4 \mu \mathrm{mol} / \mathrm{L}$ DATS.

3.3. Alteration of P-gp Expression. DATS-treated K562/A02 cells were incubated with phycoerythrin-conjugated UIC2, and then detected by FCM. The expression of P-gp in K562 was lower than that in K562/A02 $(P<0.01)$. After treatment with DATS in K562/A02 cells, P-gp expression decreased. A significant difference was observed between untreated K562/A02 cells and treated K562/A02 cells $(P<0.01)$ (Figure 3).

3.4. Apoptosis Observed by Light Microscopy. Adriamycin $(1 \mu \mathrm{g} / \mathrm{mL})$ alone did not inhibit the proliferation of K562/A02 cells significantly (Figures 4(a) and 4(b)). After simultaneous treatment of adriamycin $(1 \mu \mathrm{g} / \mathrm{mL})$ with DATS $(2 \mu \mathrm{mol} / \mathrm{L})$ for $24 \mathrm{~h}$, the proliferation of $\mathrm{K} 562 / \mathrm{A} 02$ cells slowed down (Figure 4(c)). After 48 h, the K562/A02 cells showed cell shrinkage, chromatin condensation, margination, nuclear fragmentation, apoptotic bodies, and typical apoptotic cytomorphological features (Figure 4(d)). After $72 \mathrm{~h}$, more apoptotic cells and less surviving K562/A02 cells were detected (Figure 4(e)).

3.5. Apoptosis Statistical FCM Assay. Apoptosis of K562/A02 cells was induced by DATS or verapamil. After incubation with either DATS $(2 \mu \mathrm{mol} / \mathrm{L})$ or verapamil $(4 \mu \mathrm{g} / \mathrm{mL})$ for
$48 \mathrm{~h}$, apoptotic percentages of K562/A02 cells were $12.15 \pm$ $0.78 \%$ and $11.55 \pm 1.91 \%$, respectively. Evident differences were found compared with the control $(0.9 \pm 0.17 \%, P=$ 0.000) (Figure 5).

3.6. Detection of Gene Expression. As demonstrated by semiquantitative RT-PCR, overexpression of mdr1 mRNA was detected better in the K562/A02 cells compared with the K562 cells $(P<0.05)$. The K562/A02 cells expressed highlevels of $\mathrm{NF}-\kappa \mathrm{B} / \mathrm{p} 65$, but expressed low-levels of $\mathrm{I} \kappa \mathrm{B} \alpha$ and caspase-3. DATS could downregulate the expression of mdr1 and NF- $\kappa \mathrm{B} / \mathrm{p} 65(P<0.05)$ and upregulate the expression of caspase-3 $(P<0.05)$. However, DATS cannot evidently increase the expression level of $\mathrm{I} \kappa \mathrm{B} \alpha(P>0.05)$ (Figure 6).

3.7. Western Blot Analysis of Protein Expression. The Western blot report revealed that the expression of mdr1 protein and NF- $\kappa \mathrm{B} / \mathrm{p} 65$ protein were much higher in K562/A02 cells compared with those in $\mathrm{K} 562$ cells $(P<0.05)$. The expression level of $\mathrm{I} \kappa \mathrm{B} \alpha$ protein and caspase- 3 protein in K562/A02 cells was much lower than that in K562 cells $(P<0.05)$. DATS could downregulate the expression of mdr1 and NF$\kappa \mathrm{B} / \mathrm{p} 65(P<0.05)$ and upregulate the expression of caspase$3(P<0.05)$. However, DATS cannot evidently increase the expression level of $\mathrm{I} \kappa \mathrm{B} \alpha(P>0.05)$ (Figure 7).

\section{Discussion}

In the present study, we have shown that DATS can significantly reverse the MDR of K562/A02 cells in vitro by increasing intracellular adriamycin concentration through downregulating the overexpression of $\mathrm{P}$-gp and inducing apoptosis via increased caspase- 3 expression. More importantly, we have proved that the NF- $\kappa \mathrm{B}$ signaling pathway is involved in the reversal mechanism of DATS.

The active efflux of xenobiotics is a major mechanism of cell adaptation to environmental stress. The ATP-dependent transmembrane transporter Pg-p confers long-term cell survival in the presence of different toxins, including anticancer drugs.

$\mathrm{P}$-gp, a product of the mdr- 1 gene, is a $170 \mathrm{kDa}$ ATPdependent transmembrane transporter that acts as a drug efflux pump, decreasing intracellular drug accumulation and therefore reducing intracellular drug efficacy [2, 3]. A high P-gp expression level is usually observed in MDR cell lines. However, in sensitive cells, P-gp is usually not detected. The drug intake capacity of cells with high mdr-1 gene expression 


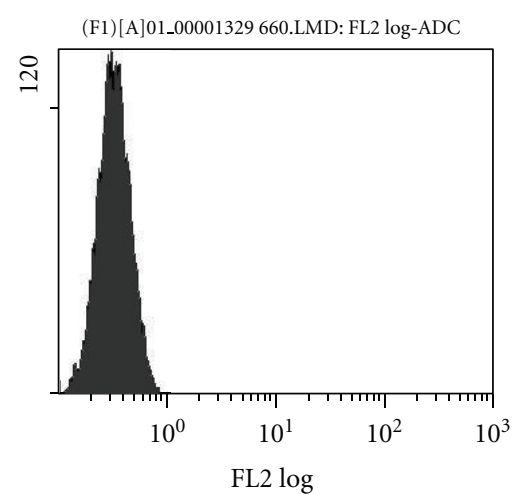

(a) K562 cells

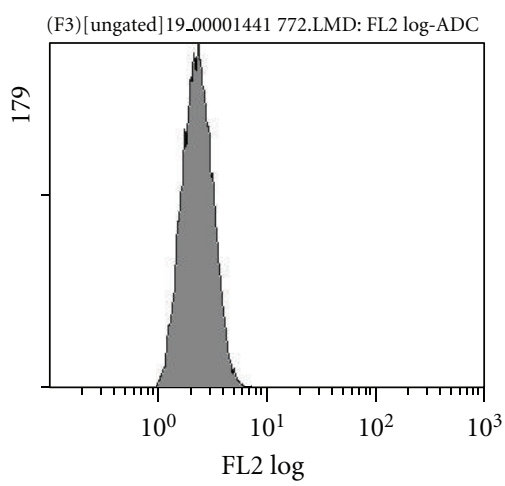

(d) K562/A02 cells + ADM (adriamycin)

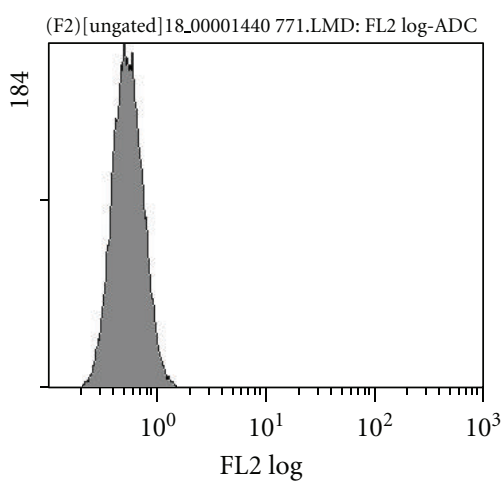

(b) K562/A02 cells

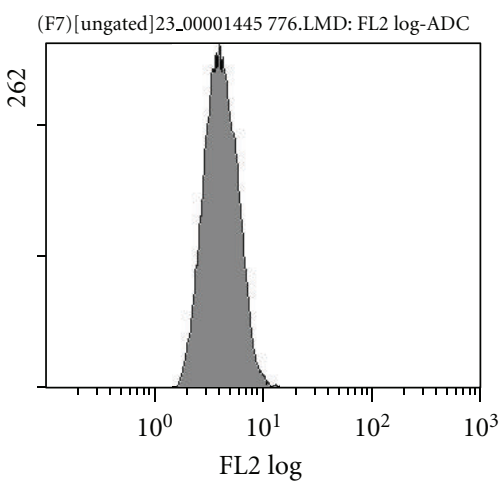

(e) K562/A02 cells + DATS + ADM (adriamycin)

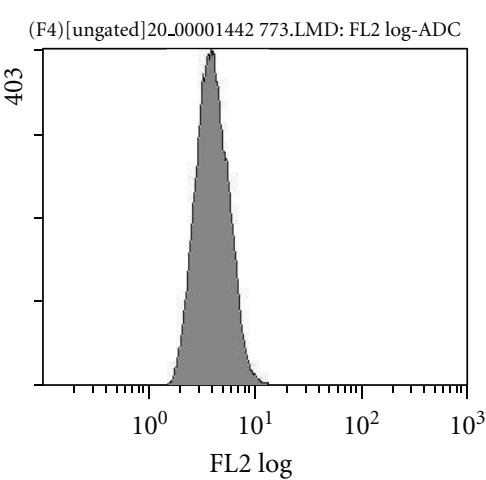

(c) K562 cells + ADM (adriamycin)

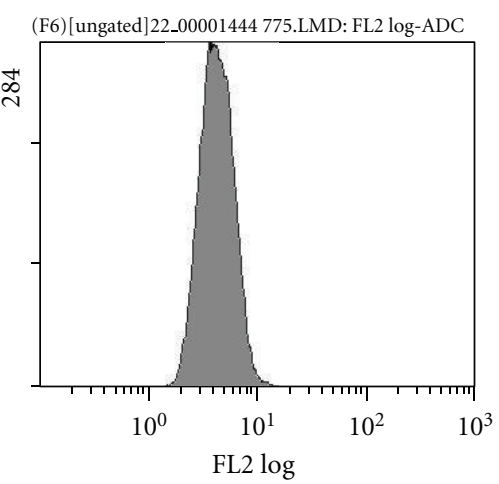

(f) K562/A02 cells + VRP (verapamil) + ADM (adriamycin)

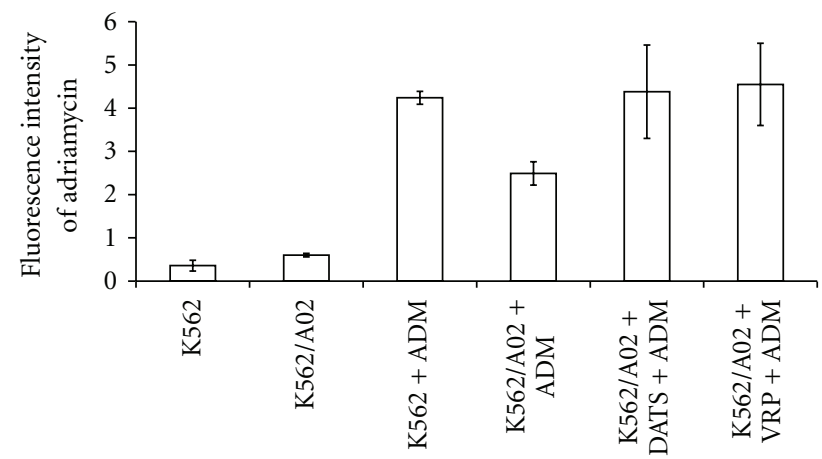

(g) K562/A02 cells were treated with DATS $(2 \mu \mathrm{mol} / \mathrm{L})$ or verapamil $(4 \mathrm{mg} / \mathrm{L})$ for $48 \mathrm{~h}$, then adriamycin $(5 \mathrm{mg} / \mathrm{L})$ was added and coincubated for a further $2 \mathrm{~h}$

FIgURE 2: Concentration of adriamycin in K562 or K562/A02 cells.

levels have no difference compared with sensitive cells, but drug efflux capacity is significantly increased [31,32].

MDR is one of the major causes of failure in leukemic chemotherapy and is associated with the overexpression of P-gp in leukemic cell membranes. Studies have shown that in acute myeloid leukemia patients, the clinical remission (CR) rate of original leukemia cells with P-gp expression is 50\%, whereas the CR rate of P-gp-negative cells is $81 \%$. The $\mathrm{P}$ gp expression in recrudescent leukemia group is significantly higher than in the first treatment group.

Enormous efforts have been exerted to find reversal agents of the drug efflux pump and overcome MDR. Various compounds, such as verapamil, cyclosporin, quinidine, tamoxifen, progesterone, reserpine, and others, have been reported to overcome MDR in vitro by decreasing mdr-1 expression [4]. However, their clinical application is limited due to their unacceptable side effects or toxicity at the doses required for effectiveness.

Plant-derived drugs or herbal formulations have multitarget functions and have low toxicity. Recently, traditional Chinese medicine and its extracts have been shown to have high reversal activity on MDR. Yu et al. proved that carnosic acid (CA) can reverse the MDR of K562/A02 cells in vitro by increasing intracellular adriamycin concentration, downregulating the expression of mdrl, and inhibiting the function of P-gp [10]. Chen et al. found that puerarin can reverse 


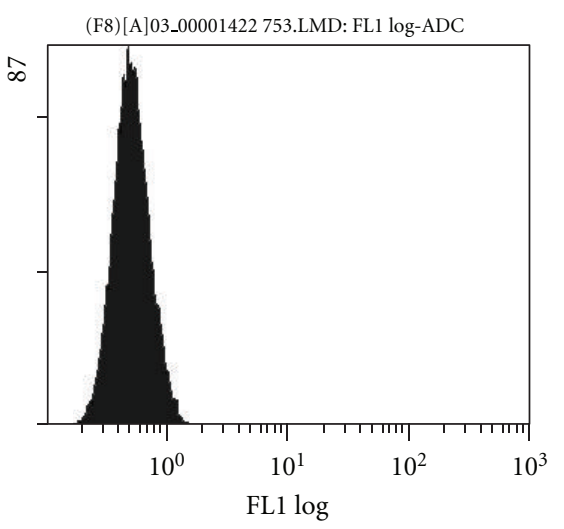

(a) K562 cells

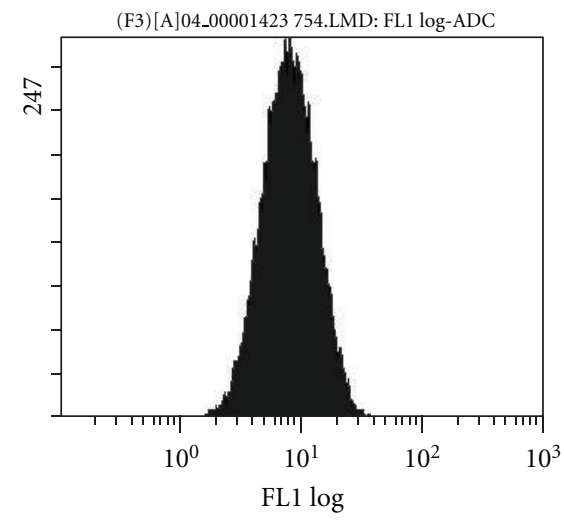

(b) K562/A02 cells

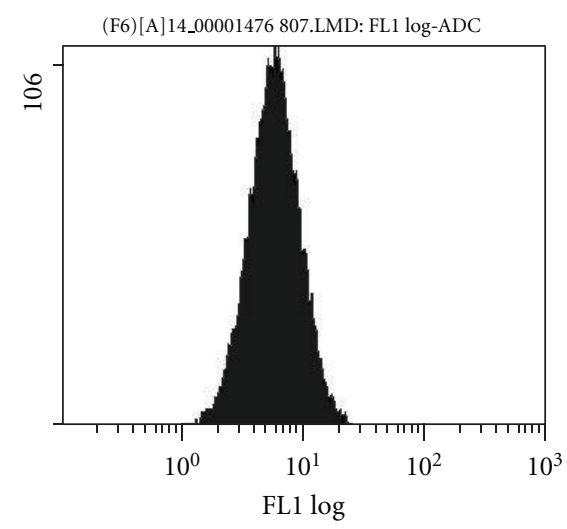

(c) K562/A02 cells + DATS

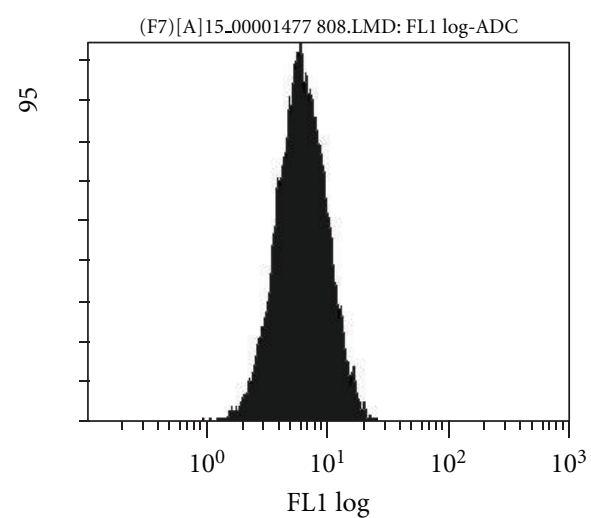

(d) K562/A02 cells + VRP (verapamil)

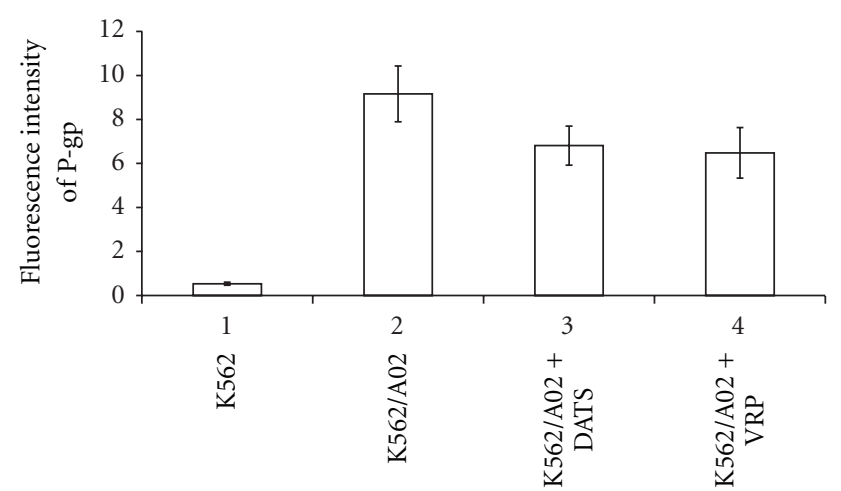

(e) DATS $(2 \mu \mathrm{mol} / \mathrm{L})$ or verapamil $(4 \mathrm{mg} / \mathrm{L})$ treated K562/A02 cells were incubated with phycoerythrin-conjugated UIC2, and then were detected by FCM

FIgURE 3: The expression of P-gp on the membrane surface of K562 or K562/A02 cells.

the multidrug resistance of K562/A02 to ADR by inhibiting the expression of p-gp and survivin [11]. Ye discovered that ampelopsin (AMP) could increase the cytotoxicity and intracellular accumulation of chemotherapeutic drugs in MDR-associated tumor cells by inhibiting the efflux of drugs by P-gp [12].

DATS is the main sulfuric compound of garlic, and garlic has been confirmed to be beneficial to human health via multiple mechanisms. Arora et al. discovered that nontoxic concentration of DATS enhances the cytotoxic effects of VBL and VCR in VBL-resistant human leukemia (K562/R) cells in a time-dependent manner by decreasing the expression levels of P-gp [33]. However, Lai et al. proved that DAS, DADS, and DATS promote expression of mdr1 genes in colo 205 human colon cancer cells [34]. Therefore, the reversal effect of DATS to multidrug resistance is still controversial.

In the current study, we showed through MTT assays that DATS enhances the toxicity of adriamycin in K562/A02. The MDR leukemia cell line K562/A02 was established through in vitro selection of $\mathrm{K} 562$ cells with an increasing concentration of adriamycin [35] overexpressing the mdr1 gene and Pgp. DATS could decrease the IC50 of adriamycin against K562/A02 cells, as well as increase its chemosensitivity, which means DATS could reverse MDR. The fluorescence intensity value of adriamycin measured via FCM reinforced the finding that DATS could increase the toxicity of adriamycin by increasing intracellular adriamycin concentration.

We used FCM to detect P-gp protein expression on the K562/A02 cell surface, which determined whether DATS could reduce P-gp expression. After treatment with DATS, P-gp expression decreased significantly, which demonstrated that DATS could reverse MDR by inhibiting P-gp overexpression. The decreased expression of P-gp was consistent with the downregulation of the mdrl gene and protein, as demonstrated by RT-PCR and Western blot. The result was similar to the report of Arora. But its molecular mechanism is still not fully understood.

We found that the intracellular adriamycin concentration in DATS-treated K562/A02 cells was 1.76-fold that in untreated K562/A02 cells. The extent of drug resistance reversal to adriamycin of DATS-treated K562/A02 cells was 3.79-fold that of untreated K562/A02 cells. Thus, other factors probably play important roles in the MDR mechanism, besides the reduction of intracellular drug accumulation.

In recent years, studies have shown that apoptosis is closely related to MDR. Many anticancer drugs with different structures and different targets can induce apoptosis in tumor cells. The mechanism of apoptosis may be involved in 


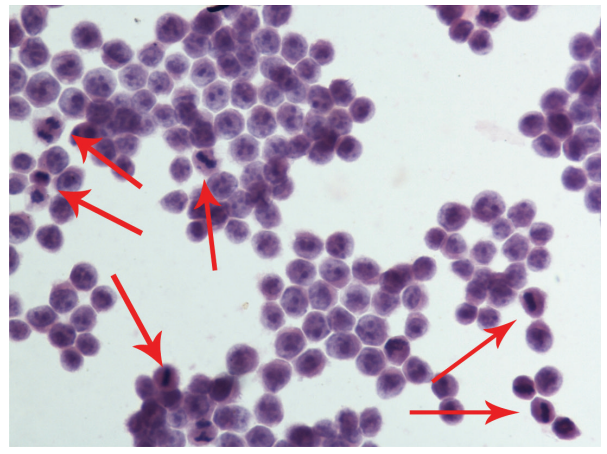

(a) K562/A02 cells grown 48 hours without drugs (400 magnification). Cells proliferated actively, mitotic easy to see (shown with $\uparrow$ )

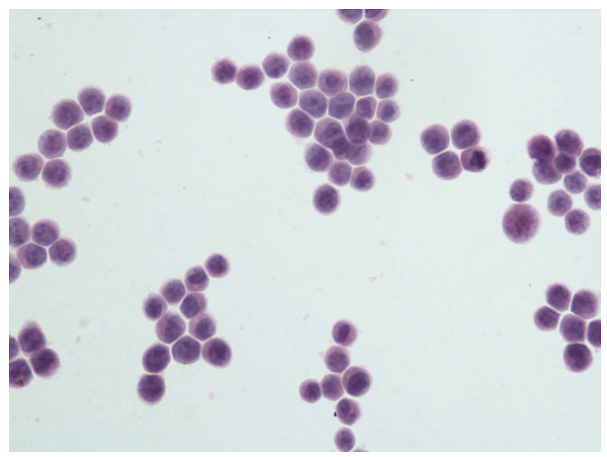

(c) K562/A02 cells grown 24 hours with adriamycin and DATS $(2 \mu \mathrm{mol} / \mathrm{L})$ (400 magnification). Proliferation of K562/A02 cells slowed down, mitotic rarely to see

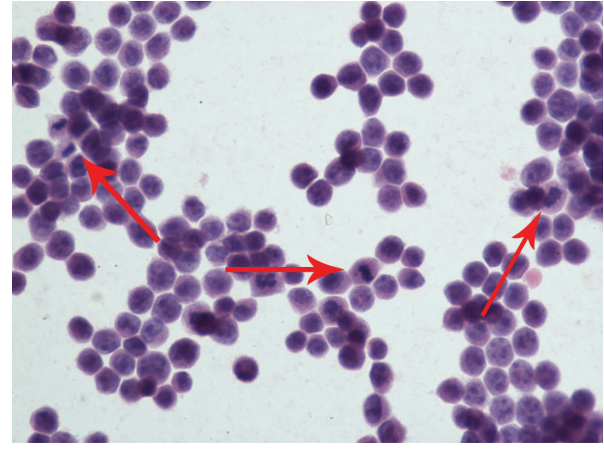

(b) K562/A02 cells grown 48 hours with adriamycin $(1 \mu \mathrm{g} / \mathrm{mL})$ (400 magnification). Cells proliferated actively, mitotic easy to see (shown with $\uparrow$ )

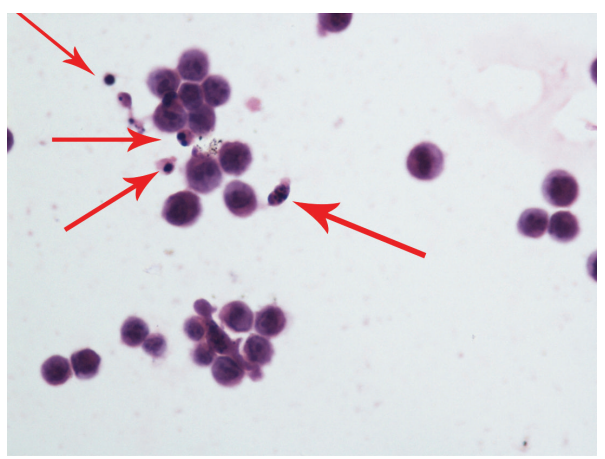

(d) K562/A02 cells grown 48 hours with adriamycin and DATS (400 magnification). K562/A02 cells showed cell shrinkage, chromatin condensation, margination, nuclear fragmentation, apoptotic bodies easy to see (shown with $\uparrow$ )

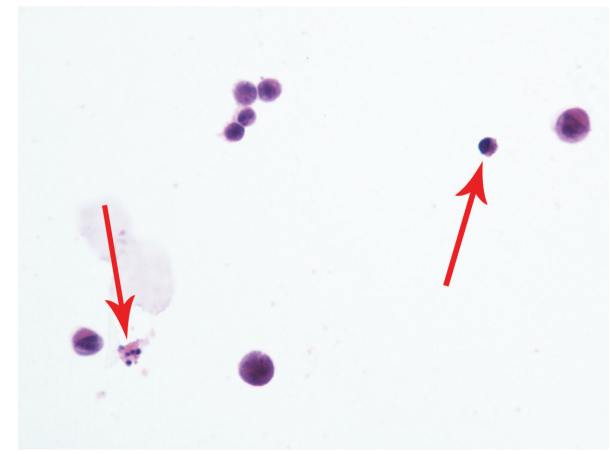

(e) K562/A02 cells grown 72 hours with adriamycin and DATS (400 magnification). Survival rate of K562/A02 cells reduced, apoptotic bodies easy to see (shown with $\uparrow$ )

FIGURE 4: Morphology observed by light microscopy.

the mechanism of MDS. Apoptosis is the common pathway of many different drugs. Due to the inhibition of apoptosis, the tumor cells are not only resistant to a certain drug, but are resistant to other drugs at the same time. This phenomenon leads to MDR.

We compared the morphological changes of cells with HE staining by light microscopy. As shown in Figure 4, the effect of DATS combined with a small dose of chemotherapeutic agent on K562/A02 cells resulted in strikingly increased apoptosis. At the same time, the apoptosis rate of
K562/A02 cells induced by DATS was measured using flow cytometric assay. The proapoptotic mechanism played an important role in the process of reversal of MDR by DATS, as revealed by evidence.

The caspase family, a large class of proteases, plays a very important role in the activation and execution of apoptosis. Thus, some researchers have named them the effectors of apoptosis. In the caspase family, caspase- 3 is the key element of implementation because it participates in many apoptotic signaling pathways. The weakened expression of caspase- 3 


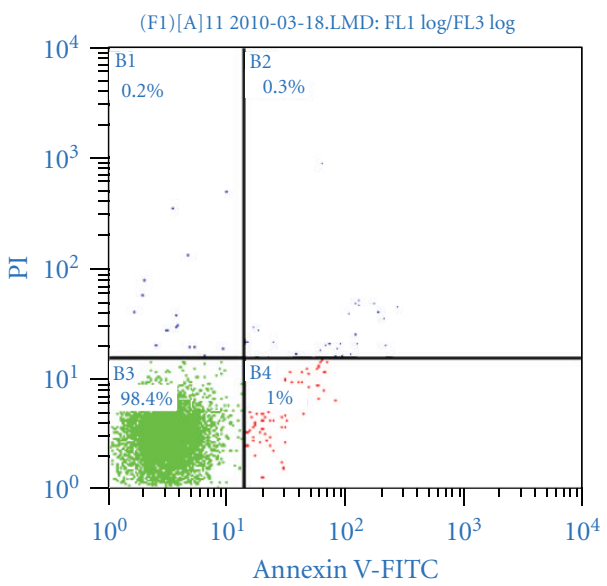

(a) K562/A02 cells

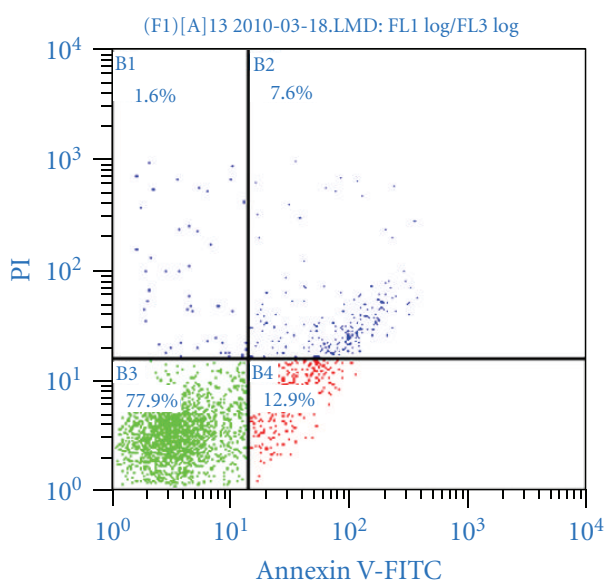

(c) K562/A02 cells + VRP (verapamil)

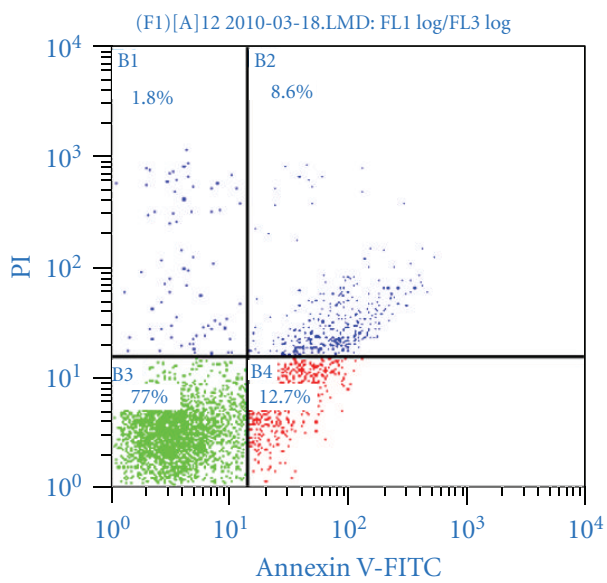

(b) K562/A02 cells + DATS

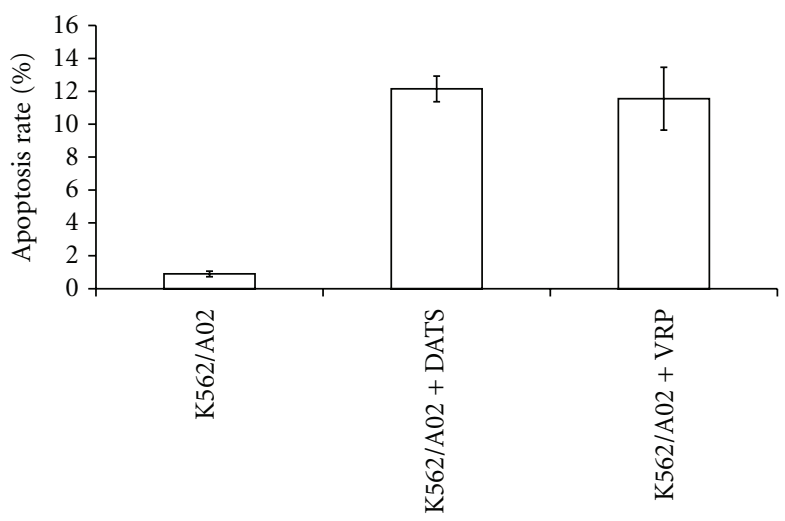

(d) In the medium containing different drugs $(2 \mu \mathrm{mol} / \mathrm{L}$ DATS or $4 \mathrm{mg} / \mathrm{L}$ verapamil) at $37^{\circ} \mathrm{C}$ for $48 \mathrm{~h}$, cell labeling was performed using annexin $\mathrm{V}$ conjugated to FITC

FIgURE 5: Apoptosis of K562/A02 cells induced by DATS or verapamil.

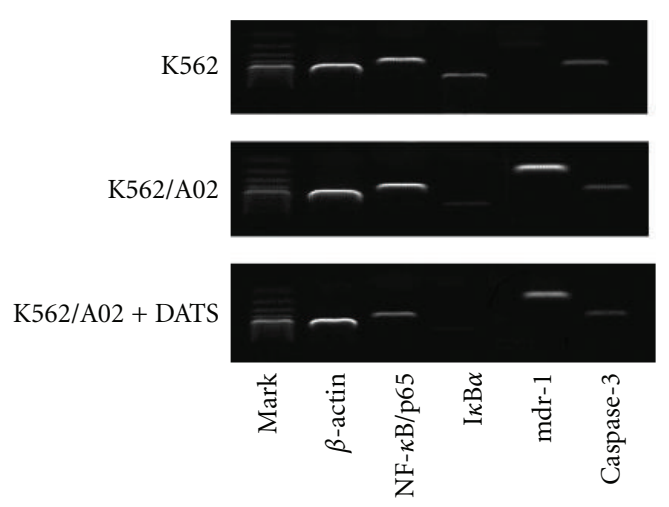

(a)

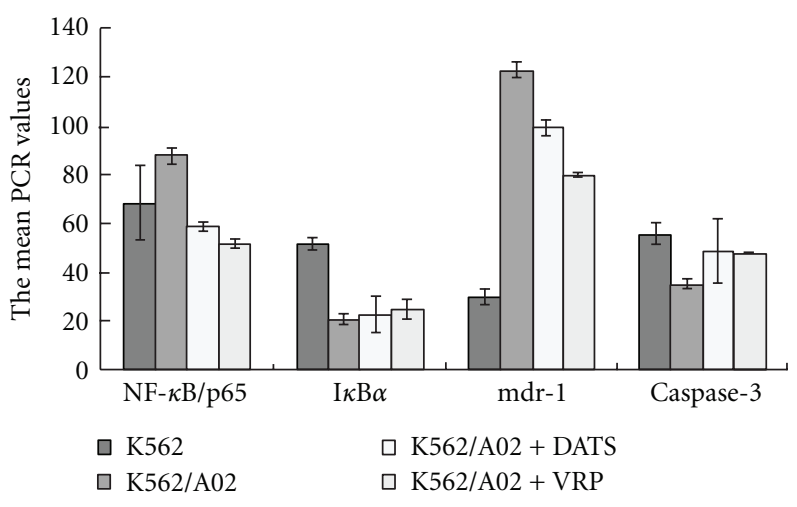

(b)

Figure 6: The mean PCR values of the ratio relative to the $\beta$-actin gene DATS $(2 \mu \mathrm{mol} / \mathrm{L})$ or verapamil $(4 \mathrm{mg} / \mathrm{L})$ treated $\mathrm{K} 562$ cells and K562/A02 cells. 


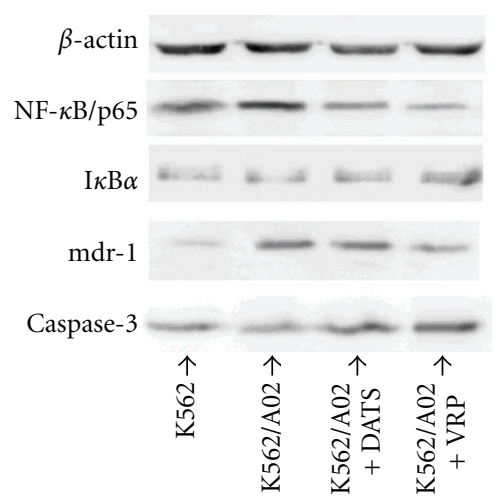

(a)

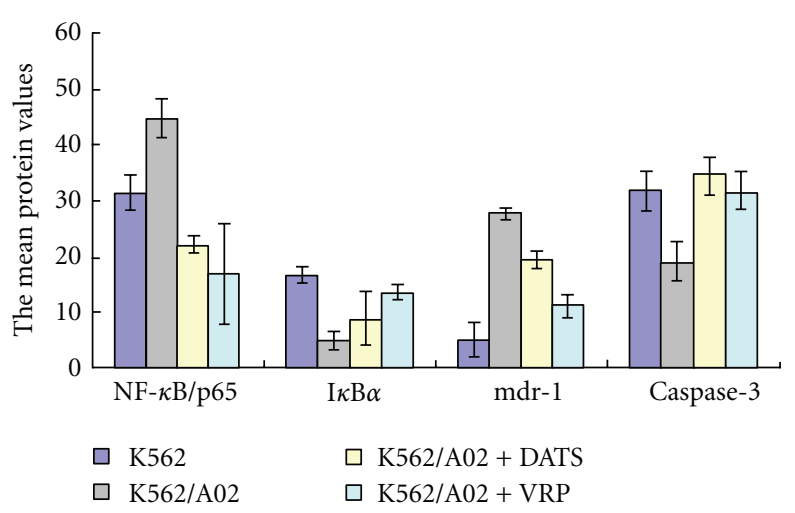

(b)

Figure 7: The mean protein values of the ratio relative to the $\beta$-actin DATS $(2 \mu \mathrm{mol} / \mathrm{L})$ or verapamil $(4 \mathrm{mg} / \mathrm{L})$ treated K562 cells and K562/A02 cells.

has been associated with drug resistance and apoptotic inhibition in hematologic malignancies [36, 37]. The induced cell death in K562-Vinc cells was associated with activation of caspase-3 [38]. Several studies have documented that garlic can increase the activation of caspase-3 [39-41]. The current study arrived at the same conclusion. The ratio of caspase3 expression in drug-resistant strains was significantly lower than in the sensitive strains. DATS could upregulate caspase3 protein significantly in K562/A02 cells, which means DATS can promote apoptosis by adjusting caspase-3 expression.

As revealed in the current experiment, DATS can reverse the MDR of K562/A02 cells by increasing intracellular adriamycin concentration via downregulating the overexpression of P-gp and inducing apoptosis by activating increased caspase-3 expression. However, no research has yet indicated the signaling pathway through which DATS can adjust these genes.

The importance of NF- $\kappa \mathrm{B}$ in the process of cancerization has been mentioned in previous research. NF- $\kappa \mathrm{B}$ proteins are a small group of related and evolutionarily conserved proteins, in which mammals consists of five members, namely, Rel (c-Rel), RelA/p65, RelB, p50, and p52. In resting cells, NF- $\kappa \mathrm{B}$ is sequestered in the cytoplasm through the inhibitory molecule, termed inhibitor of NF- $\kappa \mathrm{B}(\mathrm{I} \kappa \mathrm{B})$, such as $\mathrm{I} \kappa \mathrm{B} \alpha$, which masks the nuclear localization sequence of NF- $\kappa$ B. The stimulation of cells with various stimuli, including the stimulation of the TCR signaling pathway, leads to the activation of the I $\kappa \mathrm{B}$ kinase (IKK). NF- $\kappa \mathrm{B}$ signaling can be dichotomized into a "classical" pathway in which $\mathrm{I} \kappa \mathrm{B}$ kinase $(\mathrm{IKK} \beta)$ phosphorylates $\mathrm{I} \kappa \mathrm{B} \alpha$. An "alternative" NF- $\kappa \mathrm{B}$ pathway exists, in which IKK $\alpha$ phosphorylates the p100 precursor of the NF- $\kappa \mathrm{B}$ p52 subunit. The activated IKK phosphorylates $\mathrm{I} \kappa \mathrm{B}$, triggering rapid ubiquitination and degradation of $\mathrm{I} \kappa \mathrm{B}$ by the $26 \mathrm{~S}$ proteasome complex, which unmasks the nuclear localization sequence of NF$\kappa \mathrm{B}$. Therefore, NF- $\kappa \mathrm{B}$ can be rapidly translocated into the nucleus to initiate the transcription of its target genes. The result of these signaling events is the accumulation of the heterodimeric NF- $\kappa \mathrm{B}$ transcription factors in the nucleus, with the classical pathway regulating mainly p50/p65 and
p50/c-Rel dimers, and the alternative pathway regulating p52/relB dimers [42].

NF- $\kappa \mathrm{B}$ can intervene in oncogenesis by regulating the expression of a large number of genes that regulate apoptosis, cell proliferation and differentiation, as well as inflammation, angiogenesis, and tumor migration [43]. Therefore, the inhibition of NF- $\kappa \mathrm{B}$ has been proposed as an adjuvant therapy for cancer. Many Phase I and II clinical studies involving different inhibitors are underway. Previous studies have proven that some Chinese medicines, such as GuanJen-Huang, can induced apoptosis by inhibiting NF- $\kappa \mathrm{B}$ activation [44].

A constitutive NF- $\kappa \mathrm{B}$ activity has been observed in several hematological malignancies, and this is associated with its antiapoptotic role $[45,46]$. NF- $\kappa$ B could participate in the chemoresistance of tumor cells mediated by the expression of the MDR protein. As previously confirmed, NF- $\kappa \mathrm{B}$ can increase the MDR gene expression in tumor cells. A purified NF- $\kappa$ B binding sequence (5'2 CCTTTCGGGG23') was found in the first exon of the mdr-1 promoter region, which confirmed that there are binding sites of NF- $\kappa \mathrm{B}$ in the mdr-1 gene. Mdr-1 may thus be NF- $\kappa \mathrm{B}$ downstream genes [47]. Furthermore, previous literature has confirmed that anticancer drugs, such as adriamycin and other chemicals, can damage tumor cell DNA, which can lead to the activation of NF- $\kappa \mathrm{B}$. Activated NF- $\kappa \mathrm{B}$ promotes the transcription of mdr-1 via NF- $\kappa$ B binding sites. Therefore, if the expression of NF- $\kappa \mathrm{B}$ can be inhibited, the sensitivity of chemotherapy can be increased [11, 48-50].

We have proved that K562/A02 cells display higher levels of NF- $\kappa \mathrm{B} / \mathrm{p} 65$ protein expression than K562 cells. DATS can regulate the expression of NF- $\kappa \mathrm{B} / \mathrm{p} 65$. In K562/A02 cells, the expression of P-gp and mdr-1 are positively correlated with NF- $\kappa \mathrm{B} / \mathrm{p} 65$. Therefore, one of the mechanisms of NF- $\kappa \mathrm{B}$ antiapoptotic regulation in K562/A02 cells is correlated with mdr- 1 and P-gp expression. Inhibition of NF- $\kappa$ B activation may be involved in the reversal of MDR in K562/A02 cells by DATS.

Although the molecular mechanism of NF- $\kappa \mathrm{B}$ activation in leukemic stem cells or AML blasts remains elusive at present, NF- $\kappa \mathrm{B}$ and its unique role in the apoptotic and proli- 
feration pathways and in drug resistance could represent an attractive target of selective drugs. NF- $\kappa \mathrm{B}$ inhibition has been proposed as an adjuvant therapy for cancer [47].

In conclusion, the present study has demonstrated that DATS can serve as a novel, nontoxic modulator of MDR and can reverse the MDR of K562/A02 cells in vitro by increasing intracellular adriamycin concentration, downregulating mdr-1 expression, and inducing apoptosis by activating increased caspase- 3 expression. We therefore conclude for the first time that DATS can block NF- $\kappa \mathrm{B}$ activation, which produces the downstream inhibitory effects on chemotherapy sensitivity and apoptosis of K562/A02 cells. DATS could be a highly feasible candidate for the development of a new MDR reversal agent.

\section{Authors' Contribution}

Q. Xai and Z.-Y. Wang contributed equally to this work.

\section{Acknowledgment}

This work was supported by the National Nature Science Foundation of China (no. 30600258).

\section{References}

[1] M. M. Gottesman, T. Fojo, and S. E. Bates, "Multidrug resistance in cancer: role of ATP-dependent transporters," Nature Reviews Cancer, vol. 2, no. 1, pp. 48-58, 2002.

[2] J. P. Gillet, T. Efferth, and J. Remacle, "Chemotherapyinduced resistance by ATP-binding cassette transporter genes," Biochimica et Biophysica Acta, vol. 1775, no. 2, pp. 237-262, 2007.

[3] M. Mimeault, R. Hauke, and S. K. Batra, "Recent advances on the molecular mechanisms involved in the drug resistance of cancer cells and novel targeting therapies," Clinical Pharmacology and Therapeutics, vol. 83, no. 5, pp. 673-691, 2008.

[4] M. Inaba, R. Fujikura, S. Tsukagoshi, and Y. Sakurai, "Restored in vitro sensitivity of adriamycin- and vincristine-resistant P388 leukemia with reserpine," Biochemical Pharmacology, vol. 30, no. 15, pp. 2191-2194, 1981.

[5] J. M. Ford and W. N. Hait, "Pharmacology of drugs that alter multidrug resistance in cancer," Pharmacological Reviews, vol. 42, no. 3, pp. 155-199, 1990.

[6] A. F. List, K. J. Kopecky, C. L. Willman et al., "Benefit of cyclosporine modulation of drug resistance in patients with poor-risk acute myeloid leukemia: a Southwest Oncology Group study," Blood, vol. 98, no. 12, pp. 3212-3220, 2001.

[7] C. Y. Chang, H. L. Chan, H. Y. Lin et al., "Rhein induces apoptosis in human breast cancer cells," Evidence-Based Complementary and Alternative Medicine, vol. 2012, Article ID 952504, 8 pages, 2012.

[8] H. W. Lai, S. Y. Chien, S. J. Kuo et al., "The potential utility of curcumin in the treatment of HER-2-overexpressed breast cancer: an in vitro and in vivo comparison study with herceptin," Evidence-Based Complementary and Alternative Medicine, vol. 2012, Article ID 486568, 12 pages, 2012.

[9] P. N. Chen, M. L. Ho, Y. S. Hsieh et al., "Antimetastatic potentials of Dioscorea nipponica on melanoma in vitro and in vivo," Evidence-Based Complementary and Alternative Medicine, vol. 2011, Article ID 507920, 13 pages, 2011.
[10] X. N. Yu, X. L. Chen, H. Li, X. X. Li, H. Q. Li, and W. R. Jin, "Reversion of P-glycoprotein-mediated multidrug resistance in human leukemic cell line by carnosic acid," The Chinese journal of physiology, vol. 51, no. 6, pp. 348-356, 2008.

[11] J. W. Chen, S. Tao, R. Luo, G. S. Zhang, and Y. X. Xu, "Molecular mechanism of reversing multi-drug resistance of K562/AO2 by puerarin," Zhong Nan Da Xue Xue Bao Yi Xue Ban, vol. 33, no. 3, pp. 216-221, 2008.

[12] J. Ye, Y. Zheng, and D. Liu, "Reversal effect and its mechanism of ampelopsin on multidrug resistance in K562/ADR cells," Zhongguo Zhongyao Zazhi, vol. 34, no. 6, pp. 761-765, 2009.

[13] P. D. L. Chao, S. P. Lin, P. P. Wu et al., "Different influences on tacrolimus pharmacokinetics by coadministrations of Zhi Ke and Zhi Shi in rats," Evidence-based Complementary and Alternative Medicine, vol. 2011, Article ID 751671, 6 pages, 2011.

[14] G. W. Chen, J. G. Chung, H. C. Ho et al., "Effects of garlic compounds disllyl sulphide and diallyl disulphide on arylmine Nacetyltransferase activity in Klebsiella pneumoniae," Journal of Applied Toxicology, vol. 19, no. 2, pp. 75-81, 1999.

[15] S. Ankri and D. Mirelman, "Antimicrobial properties of allicin from garlic," Microbes and Infection, vol. 1, no. 2, pp. 125-129, 1999.

[16] R. T. Ackermann, C. D. Mulrow, G. Ramirez, C. D. Gardner, L. Morbidoni, and V. A. Lawrence, "Garlic shows promise for improving some cardiovascular risk factors," Archives of Internal Medicine, vol. 161, no. 6, pp. 813-824, 2001.

[17] L. Y. Chung, "The antioxidant properties of garlic compounds: alyl cysteine, alliin, allicin, and allyl disulfide," Journal of Medicinal Food, vol. 9, no. 2, pp. 205-213, 2006.

[18] Y. H. Siddique and M. Afzal, "Antigenotoxic effect of allicin against SCEs induced by methyl methanesulphonate in cultured mammalian cells," Indian Journal of Experimental Biology, vol. 42, no. 4, pp. 437-438, 2004.

[19] O. C. Ohaeri and G. I. Adoga, "Anticoagulant modulation of blood cells and platelet reactivity by garlic oil in experimental diabetes mellitus," Bioscience Reports, vol. 26, no. 1, pp. 1-6, 2006.

[20] D. Xiao, A. Herman-Antosiewicz, J. Antosiewicz et al., "Diallyl trisulfide-induced G2-M phase cell cycle arrest in human prostate cancer cells is caused by reactive oxygen species-dependent destruction and hyperphosphorylation of Cdc25C," Oncogene, vol. 24, no. 41, pp. 6256-6268, 2005.

[21] A. Herman-Antosiewicz and S. V. Singh, "Checkpoint kinase 1 regulates diallyl trisulfide-induced mitotic arrest in human prostate cancer cells," Journal of Biological Chemistry, vol. 280, no. 31, pp. 28519-28528, 2005.

[22] N. Li, R. Guo, W. Li et al., "A proteomic investigation into a human gastric cancer cell line BGC823 treated with diallyl trisulfide," Carcinogenesis, vol. 27, no. 6, pp. 1222-1231, 2006.

[23] A. Das, N. L. Banik, and S. K. Ray, "Garlic compounds generate reactive oxygen species leading to activation of stress kinases and cysteine proteases for apoptosis in human glioblastoma T98G and U87MG cells," Cancer, vol. 110, no. 5, pp. 1083-1095, 2007.

[24] D. Xiao, Y. Zeng, E. R. Hahm, Y. A. Kim, S. Ramalingam, and S. V. Singh, "Diallyl trisulfide selectively causes baxand bak-mediated apoptosis in human lung cancer cells," Environmental and Molecular Mutagenesis, vol. 50, no. 3, pp. 201-212, 2009.

[25] X. J. Wu, Y. Hu, E. Lamy, and V. Mersch-Sundermann, "Apoptosis induction in human lung adenocarcinoma cells by 
oil-soluble allyl sulfides: triggers pathways and modulators," Environmental and Molecular Mutagenesis, vol. 50, no. 3, pp. 266-275, 2009.

[26] D. Xiao, M. Li, A. Herman-Antosiewicz et al., "Diallyl trisulfide inhibits angiogenic features of human umbilical vein endothelial cells by causing Akt inactivation and downregulation of VEGF and VEGF-R2," Nutrition and Cancer, vol. 55, no. 1, pp. 94-107, 2006.

[27] S. Shankar, Q. Chen, S. Ganapathy, K. P. Singh, and R. K. Srivastava, "Diallyl trisulfide increases the effectiveness of TRAIL and inhibits prostate cancer growth in an orthotopic model: molecular mechanisms," Molecular Cancer Therapeutics, vol. 7, no. 8, pp. 2328-2338, 2008.

[28] S. Engdal, O. Klepp, and O. G. Nilsen, "Identification and exploration of herb-drug combinations used by cancer patients," Integrative Cancer Therapies, vol. 8, no. 1, pp. 29-36, 2009.

[29] Y. P. Gong, T. Liu, Y. Q. Jia, L. Qin, C. Q. Deng, and R. Y. O. Yang, "Comparison of Pgp- and MRP-mediated multidrug resistance in leukemia cell lines," International Journal of Hematology, vol. 75, no. 2, pp. 154-160, 2002.

[30] L. Chen, X. P. Xu, J. M. Wang et al., "Reversal of multidrug resistance in leukemia cell line by cyclosporin a combining with tamoxifen and interferon- $\alpha$, Journal of Leukemia \& Lymphoma, vol. 12, no. 3, pp. 135-138, 2003.

[31] J. L. Biedler and H. Riehm, "Cellular resistance to actinomycin $\mathrm{D}$ in Chinese hamster cells in vitro: cross-resistance, radioautographic, and cytogenetic studies," Cancer Research, vol. 30, no. 4, pp. 1174-1184, 1970.

[32] R. L. Juliano and V. Ling, "A surface glycoprotein modulating drug permeability in Chinese hamster ovary cell mutants," Biochimica et Biophysica Acta, vol. 455, no. 1, pp. 152-162, 1976.

[33] A. Arora, K. Seth, and Y. Shukla, "Reversal of P-glycoproteinmediated multidrug resistance by diallyl sulfide in K562 leukemic cells and in mouse liver," Carcinogenesis, vol. 25, no. 6, pp. 941-949, 2004.

[34] K.-C. Lai, C.-L. Kuo, H.-C. Ho et al., "Diallyl sulfide, diallyl disulfide and diallyl trisulfide affect drug resistant gene expression in colo 205 human colon cancer cells in vitro and in vivo," Phytomedicine, vol. 19, no. 7, pp. 625-630, 2012.

[35] L. Feng-Jun, "Establishment of the multidrug-resistant cell line K562/A02 and its drug-resistant properties," Zhonghua Zhong Liu Za Zhi, vol. 15, no. 2, pp. 101-103, 1993.

[36] N. Voorzanger-Rousselot, L. Alberti, and J. Y. Blay, "CD40L induces multidrug resistance to apoptosis in breast carcinoma and lymphoma cells through caspase independent and dependent pathways," BMC Cancer, vol. 6, article no. 75, 2006.

[37] J. J. Mezhir, K. D. Smith, M. C. Posner et al., "Ionizing radiation: a genetic switch for cancer therapy," Cancer Gene Therapy, vol. 13, no. 1, pp. 1-6, 2006.

[38] Y. Assef, F. Rubio, G. Coló, S. del Mónaco, M. A. Costas, and B. A. Kotsias, "Imatinib resistance in multidrug-resistant K562 human leukemic cells," Leukemia Research, vol. 33, no. 5, pp. 710-716, 2009.

[39] H. F. Lu, C. C. Sue, C. S. Yu, S. C. Chen, G. W. Chen, and J. G. Chung, "Diallyl disulfide (DADS) induced apoptosis undergo caspase-3 activity in human bladder cancer T24 cells," Food and Chemical Toxicology, vol. 42, no. 10, pp. 1543-1552, 2004.

[40] K. B. Kwon, S. J. Yoo, D. G. Ryu et al., "Induction of apoptosis by diallyl disulfide through activation of caspase-3 in human leukemia HL-60 cells," Biochemical Pharmacology, vol. 63, no. 1, pp. 41-47, 2002.
[41] S. Oommen, R. J. Anto, G. Srinivas, and D. Karunagaran, "Allicin (from garlic) induces caspase-mediated apoptosis in cancer cells," European Journal of Pharmacology, vol. 485, no. 1-3, pp. 97-103, 2004.

[42] C. Y. Wang, M. W. Mayo, R. G. Korneluk, D. V. Goeddel, and A. S. Baldwin, "NF- $\kappa$ B antiapoptosis: induction of TRAF1 and TRAF2 and c-IAP1 and c-IAP2 to suppress caspase-8 activation,” Science, vol. 281, no. 5383, pp. 1680-1683, 1998.

[43] B. B. Aggarwal, "Nuclear factor- $\kappa$ B: the enemy within," Cancer Cell, vol. 6, no. 3, pp. 203-208, 2004.

[44] Y. H. Liu, M. L. Li, M. Y. Hsu et al., "Effects of a chinese herbal medicine, Guan-Jen-Huang (Aeginetia indica Linn.), on renal cancer cell growth and metastasis," Evidence-based Complementary and Alternative Medicine, vol. 2012, Article ID 935860, 10 pages, 2012.

[45] M. Karin, Y. Cao, F. R. Greten, and Z. W. Li, "NF- $\kappa$ B in cancer: from innocent bystander to major culprit," Nature Reviews Cancer, vol. 2, no. 4, pp. 301-310, 2002.

[46] L. Bemal-Mizrachi, C. M. Lovly, and L. Ratner, "The role of NF- $\kappa$ B-1 and NF- $\kappa$ B-2-mediated resistance to apoptpsis in lymphomas," Proceedings of the National Academy of Sciences, vol. 103, no. 24, pp. 9220-9222, 2006.

[47] M. Bentires-Alj, V. Barbu, M. Fillet et al., "NF- $\kappa$ B transcription factor induces drug resistance through MDR1 expression in cancer cells," Oncogene, vol. 22, no. 1, pp. 90-97, 2003.

[48] S. Kokura, N. Yoshida, N. Sakamoto et al., "The radical scavenger edaravone enhances the anti-tumor effects of CPT11 in murine colon cancer by increasing apoptosis via inhibition of NF- $\kappa$ B," Cancer Letters, vol. 229, no. 2, pp. 223233, 2005.

[49] J. H. Um, C. D. Kang, B. G. Lee, D. W. Kim, B. S. Chung, and S. H. Kim, "Increased and correlated nuclear factor-kappa B and $\mathrm{Ku}$ autoantigen activities are associated with development of multidrug resistance," Oncogene, vol. 20, no. 42, pp. 60486056, 2001.

[50] Y. G. Lin, A. B. Kunnumakkara, A. Nair et al., "Curcumin inhibits tumor growth and angiogenesis in ovarian carcinoma by targeting the nuclear factor- $\kappa \mathrm{B}$ pathway," Clinical Cancer Research, vol. 13, no. 11, pp. 3423-3430, 2007. 


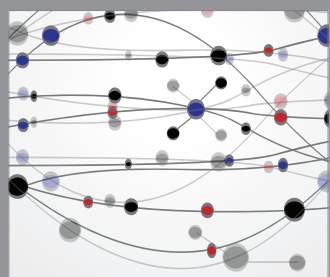

The Scientific World Journal
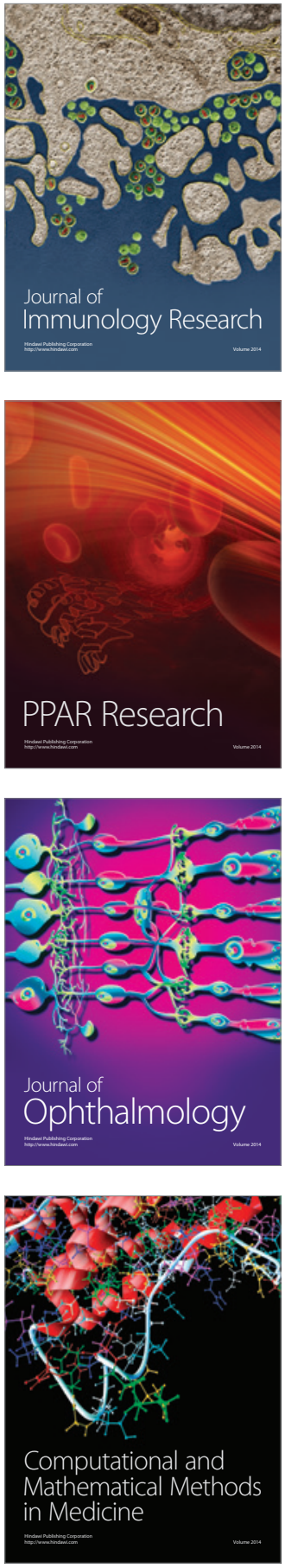

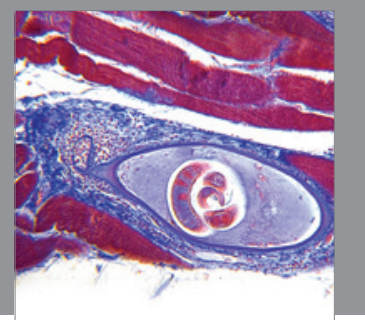

Gastroenterology

Research and Practice
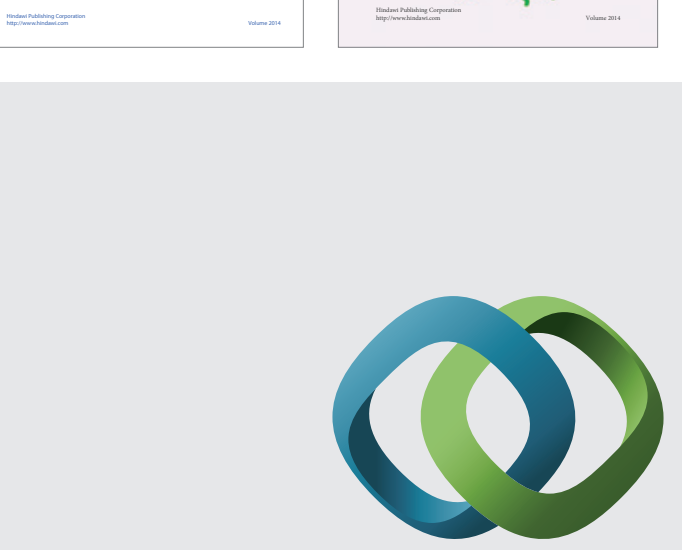

\section{Hindawi}

Submit your manuscripts at

http://www.hindawi.com
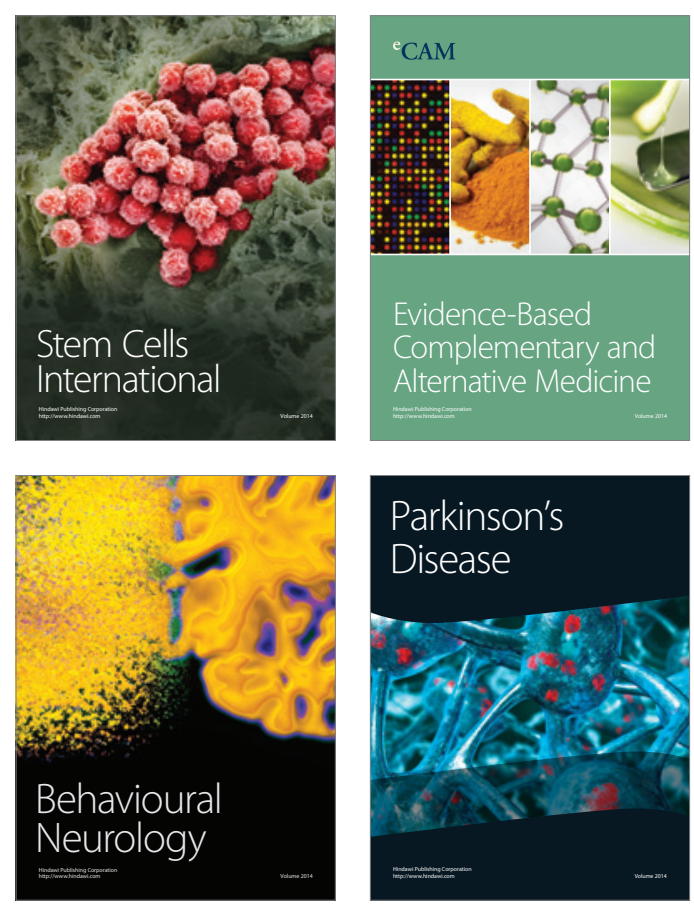

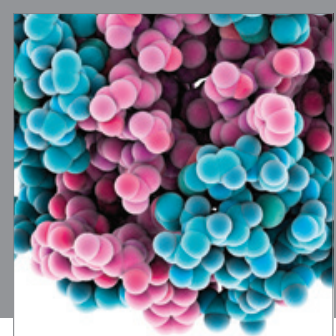

Journal of
Diabetes Research

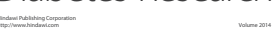

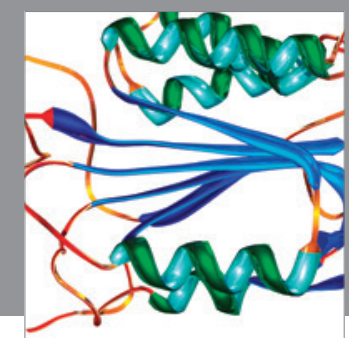

Disease Markers
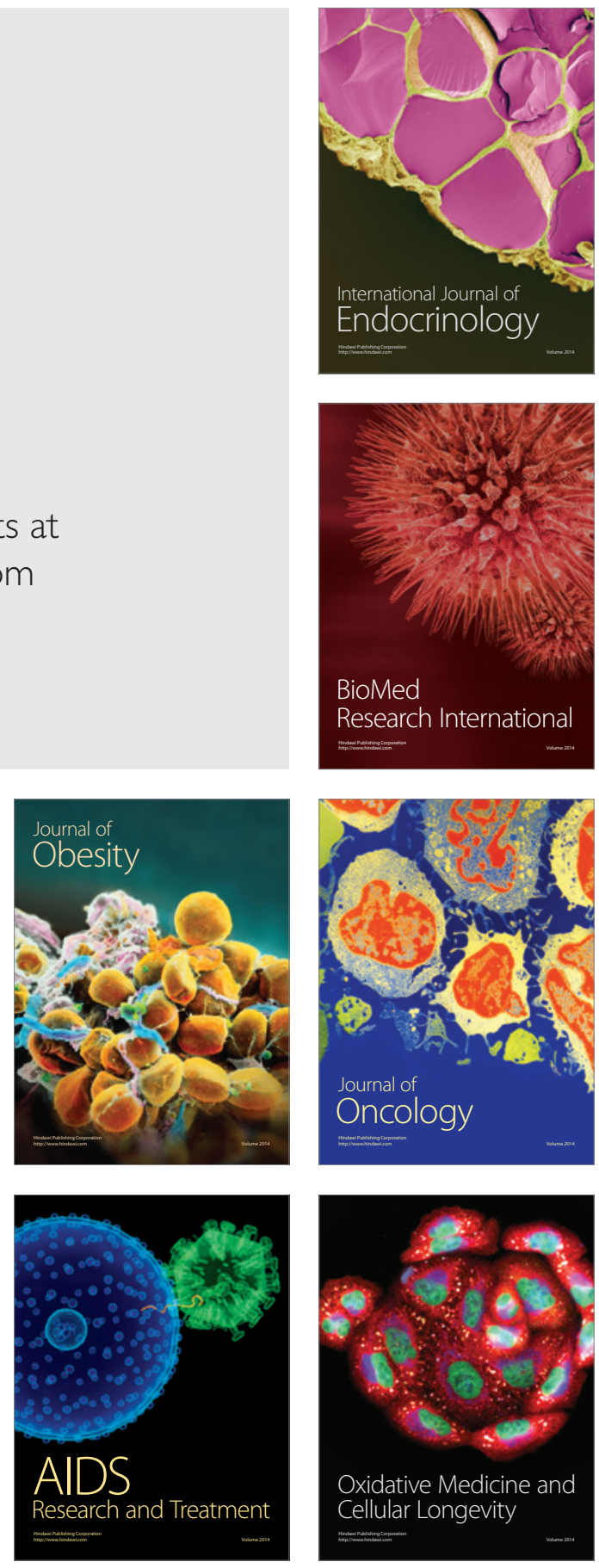